\title{
Silver Nitrate and Putrescine Enhance in vitro Shoot Organogenesis in Polygonum tinctorium
}

\author{
Jae Kwang Kim¹, Thanislas Bastin Baskar² and Sang Un Park ${ }^{2 *}$ \\ ${ }^{1}$ Division of Life Sciencesand Bio-Resource and Environmental Center, \\ Incheon National University, Incheon 406-772, Korea. \\ ${ }^{2}$ Department of Crop Science, Chungnam National University, \\ 99 Daehak-ro, Yuseong-Gu, Daejeon, 305-764, Korea. \\ http://dx.doi.org/10.13005/bbra/2002
}

(Received: 04 February 2016; accepted: 14 March 2016)

\begin{abstract}
Polygonum tinctorium, also known as indigo plant, is widely distributed in Japan. Only few studies have investigated the regeneration of the indigo plant. The aim of this study was to develop an efficient protocol for shoot regeneration and shoot elongation. Shoot organogenesis and plant regeneration from internode explants of $P$. tinctorium were improved using the ethylene inhibitor silver nitrate $\left(\mathrm{AgNO}_{3}\right)$ and the polyamine putrescine. Culturing of internode explants on initial shoot regeneration media (Murashige and Skoog media with 6-benzylaminopurine at $2 \mathrm{mg} / \mathrm{L}$ ) supplemented with different concentrations $\left(0,1,5,7,10,20 \mathrm{mg} \mathrm{L}^{-1}\right)$ of $\mathrm{AgNO}_{3}$ significantly improved the regeneration efficiency, resulting in higher number of shoots per explant and longer shoot length. The greatest number of shoots $(7.2 \pm 0.8)$ and shoot length $(2.1 \pm 0.1 \mathrm{~cm})$ were obtained in media supplemented with $7 \mathrm{mg} \mathrm{L}^{-1} \mathrm{AgNO}_{3}$, and further increase in the concentration of $\mathrm{AgNO}_{3}$ decreased the shoot production and shoot length. Additionally, we evaluated the effect of various concentrations $\left(0,10.30,50,100,200 \mathrm{mg} \mathrm{L}^{-1}\right)$ of putrescine on shoot regeneration and shoot length. The highest number of shoots $(7.4 \pm 0.8)$ and longest shoots $(2.2 \pm 0.1 \mathrm{~cm})$ were observed in cultures supplemented with $50 \mathrm{mg} \mathrm{L}^{-1}$ putrescine and further increase in concentration reduced the shoot regeneration and elongation. Our present study suggested that the addition of ethylene inhibitor $\mathrm{AgNO}_{3}$ and polyamine putrescine could be applied in micropropagation and plant transformation protocols of P. tinctorium.
\end{abstract}

Key words: Polygonum tinctorium, Plant regeneration, Silver nitrate, Putrescine.

Polygonum tinctorium Ait. (= Persicaria tinctoria H.Gross) is an annual herb from the Polygonaceae family cultivated throughout Southeast Asia. Polygonum tinctorium, commonly known as indigo plant, has been used by the dye industry ${ }^{1,2}$ and for thousands of years as a source of blue color in traditional staining of fabric in Japan. However, in the last decades, indigo leaves have been used in the traditional medicine in East Asia including Japan for treatment

\footnotetext{
* To whom all correspondence should be addressed. Tel: +82-42-821-5730; Fax: +82-42-822-2631; E-mail: supark@cnu.ac.kr
}

of acute disorders because of its antipyretic, analgesic, and antiphlogistic effects ${ }^{3}$. Indigo plant has also been used in eastern traditional medicine for detoxication, antinociception, and as antiinflammatory agent and antipyretic, although the accurate process of its actions is not completely understood $^{4}$. Furthermore, the species has been used as food ingredient in some local cuisine in Japan. Such a diversity of applications of this plant elicited our interest to further examine the usefulness of indigo leaves as a promising source of medicinal compounds or food additives. In recent years, many bioactive compounds were extracted from indigo plants including tryptanthrin with anticancer and anti-inflammatory effects ${ }^{5,6}$. Several 
plants such as Ban-Lan-Gen is the dry root of Isatis indigotica Fortune, Qing-Dai (Indigo naturalis) is a dark blue powder prepared from the leaves of Baphicacanthus cusia (Nees) Bremek (Acanthaceae), P. tinctorium (Polygonaceae), Isatis indigotica (Brassicaceae), Indigofera suffruticosa Mill. (Fabaceae), and Indigofera tinctoria L. (Fabaceae), all of which are also called indigo plants. All these plants contain different amounts of the blue dye indigo. Polygonum tinctorium has been used for treatment of many infectious diseases, and isolated bioactive compounds of this medicinal plant have been confirmed to possess anti-fungal, cancer chemopreventive, anti-bacterial, and antianaphylactic activities ${ }^{7-10}$. Polygonum tinctorium leaves are used as coloring agents in the cotton and textile industries due to high content of indigo and indole alkaloid distinguished by an extremely blue color ${ }^{11}$. The dying method is executed in the mixture of composted leaves with the inclusion of wheat bran, wood ash lye, and limestone at a temperature of ca. $20^{\circ} \mathrm{C}$ and $\mathrm{pH}>10$, which result in a lasting colorization of fabrics of different kind $^{12,13}$. The ethyl acetate extract from $P$. tinctorium have antioxidant activity attributed to caffeic acid and gallic acid compounds $8,14,15$.

In recent years, propagation of $P$. tinctorium from seeds in its natural habitat has declined. This process requires prolonged time due to hard seed coat. Therefore, in vitro micropropagation and regeneration have been introduced for regeneration of plants that are used in molecular biology. Plant tissue culture is the technique that is used to regenerate plants for a large-scale production under in vitro conditions using plant cell tissues and organs. This tissue culture method serves as an essential tool for both basic and applied studies as well as in the commercial production of economically important crops $^{16-18}$. Several studies reported in vitro regeneration of various plants using growth regulators such as in vitro shoot regeneration from stem internodes of $P$. tinctorium ${ }^{19}$.

Accumulation of ethylene was related to poor regeneration efficiency and lower gene transfer capability of plants produced using in vitro micropropagation ${ }^{20}$. Addition of ethylene inhibitors in the shoot regeneration medium improves the regeneration frequency. Kumar et al. ${ }^{21}$ studied the effect of different ethylene inhibitors on shoot organogenesis in several plant species. Shoot organogenesis of Gloxinia Sinningia speciosa Baill. has been enhanced by ethylene inhibitors ${ }^{22}$, and other studies confirmed that they improve shoot regeneration and transformation efficiency ${ }^{23-}$ ${ }^{25}$. In this study, we developed an efficient method for the regeneration of $P$. tinctorium plants from internode explants by using different concentrations of an ethylene inhibitor and polyamine.

\section{MATERIALSANDMETHODS}

\section{Seed sterilization and germination}

The seeds of $P$. tinctorium were obtained from the experimental farm in Chungnam National University (Daejeon, Korea). The seeds were surface sterilized with $70 \%(\mathrm{v} / \mathrm{v})$ ethanol for $30 \mathrm{~s}$ and incubated in $4.5 \%(\mathrm{v} / \mathrm{v})$ sodium hypochlorite aqueous solution together with a few drops of Tween 20 by mixing for $15 \mathrm{~min}$. The seeds were then thoroughly washed with sterilized distilled water under aseptic conditions and cultured on a solid basal medium for germination. The basal Murashige and Skoog medium (Murashige and Skoog, 1962 $)^{26}$ contained salt and vitamins supplemented with $3 \%$ sucrose and solidified with $0.7 \%(\mathrm{w} / \mathrm{v})$ plant agar. The $\mathrm{pH}$ of the medium was adjusted to $5.7-5.8$ using $1 \mathrm{~N}$ hydrochloric acid $(\mathrm{HCl})$ and $1 \mathrm{~N}$ potassium hydroxide $(\mathrm{KOH})$ before adding the plant agar and sterilized by autoclaving at $121^{\circ} \mathrm{C}$ for $20 \mathrm{~min}$. Ten sterilized seeds were inoculated per each Petri dish, and the Petri dishes were placed in a growth chamber at $25 \pm 1^{\circ} \mathrm{C}$, illumination of $35 \mu \mathrm{mol} \mathrm{s}^{-1} \mathrm{~m}^{-2}$ provided by standard cool-white fluorescent tubes, and 16-h photoperiod. The seeds germinated within one week of culture and the seedlings were then transferred to a Magenta box (Magenta LLC, Chicago, IL, USA) containing the same MS solid medium and cultured for 3 weeks for the growth improvement of plant material.

\section{Enhancement of in vitro plant regeneration}

Stem segments of $P$. tinctorium including one internode, approximately $2.0 \mathrm{~cm}$ in length, were aseptically cut from plants grown in vitro. The explants were cultured on a medium containing 50 $\mathrm{mL}$ of the respective medium used during in vitro growth in the Magenta box. In addition, for shoot 
regeneration from stem internodes, the MS medium was supplemented with $2 \mathrm{mg} \mathrm{L}^{-1}$ 6benzylaminopurine (BAP), which were added to the medium before sterilization. For enhancement of shoot regeneration, the media were optimized by testing the effect of ethylene inhibitor $\mathrm{AgNO}_{3}$ at different concentrations $(0,1,5,7,10$, and $20 \mathrm{mg}$ $\left.\mathrm{L}^{-1}\right)$. For enhancement of shoot organogenesis, we examined the effect of various concentration of the polyamine putrescine $(0,10,30,70,100$, and $200 \mathrm{mg} \mathrm{L}^{-1}$ ) in combination with $2 \mathrm{mg} \mathrm{L}^{-1} \mathrm{BAP}$ on shoot formation and growth. Plant hormones were purchased from Sigma-Aldrich Co. (St. Louis, MO, USA). Cultures were maintained in a growth chamber at $25 \pm 1{ }^{\circ} \mathrm{C}$, with a 16 -h photoperiod and illumination of $35 \mu \mathrm{mol} \mathrm{s}^{-1} \mathrm{~m}^{-2}$ provided by standard cool-white fluorescent tubes for 5 weeks.

\section{Rooting of regenerated shoots}

Regenerated shoots ( $2.0 \mathrm{~cm}$ long) were transferred into a rooting medium for root induction in a Magenta box. The rooting medium consisted of a MS medium solidified with $8 \mathrm{~g} \mathrm{~L}^{-1}$ of plant agar with $1 \mathrm{mg} \mathrm{L}^{-1}$ indole-3-butyric acid (IBA) was dispensed at $50 \mathrm{~mL}$ per culture vessel; four shoots were cultured in each culture vessel. Regenerated shoots were incubated at $25 \pm 1^{\circ} \mathrm{C}$ in a growth chamber with a 16-h photoperiod and illumination provided by standard cool-white fluorescent tubes (35 $\mu \mathrm{mol} \mathrm{s} \mathrm{m}^{-1} \mathrm{~m}^{-2}$ ) for 4 weeks. After 4 weeks of culture, the rooted plants were washed with sterile water to remove plant agar, transferred to pots containing autoclaved vermiculite, and coated with polyethylene bags for 1 week to maintain high

Table 1. Effect of different concentrations of $\mathrm{AgNO}_{3}$ on shoot regeneration from stem internode explant cultures of Polygonum tinctorium after 5 weeks of culture on shoot regeneration medium (Murashige and Skoog medium with $2 \mathrm{mg} \mathrm{L}^{-1}$ 6-benzylaminopurine)

\begin{tabular}{lcc}
\hline $\begin{array}{l}\mathrm{AgNO}_{3} \\
\left(\mathrm{mg} \mathrm{L}^{-1}\right)\end{array}$ & $\begin{array}{c}\text { No. of } \\
\text { shoots/explant }\end{array}$ & $\begin{array}{c}\text { Shoot } \\
\text { length }^{*}(\mathrm{~cm})\end{array}$ \\
\hline 0 & $4.8 \pm 0.8$ & $1.8 \pm 0.08$ \\
1 & $5.2 \pm 0.8$ & $1.9 \pm 0.1$ \\
5 & $6.2 \pm 0.8$ & $2.0 \pm 0.1$ \\
7 & $7.2 \pm 0.8$ & $2.1 \pm 0.1$ \\
10 & $6.6 \pm 0.5$ & $2.0 \pm 0.1$ \\
20 & $3.4 \pm 0.5$ & $1.5 \pm 0.1$ \\
\hline
\end{tabular}

*Values represent the mean \pm standard deviation of 50 shoots humidity. The plants were then transferred to soil and maintained in a growth chamber with a 16-h photoperiod and a night/day temperature of 18/ $20^{\circ} \mathrm{C}$ for 2 weeks. These hardened plants were then transferred to the greenhouse for further use.

\section{Statistical analysis}

The data obtained were expressed as means \pm standard deviation of 50 stem internodes tested.

\section{RESULTSAND DISCUSSION}

\section{Effect of different concentrations of $\mathrm{AgNo}_{3}$ and} putrescine on shoot regeneration and shoot length

Significant shoot regeneration was observed in P. tinctorium cultured on the MS medium with $2 \mathrm{mg} \mathrm{L}^{-1} \mathrm{BAP}$, thus corroborating the results reported previously by Park et $\mathrm{a}^{19}$. Whereas the shoot development was not significant using the same protocol. The addition of the ethylene inhibitor $\mathrm{AgNO}_{3}$ enhanced shoot regeneration and shoot elongation. Regeneration of the explant from the internode commenced 15 days after the inoculation. We examined the effect of different concentrations of $\mathrm{AgNO}_{3}$ on regeneration. The greater number of shoots developed $(7.2 \pm 0.8)$ and longer shoots $(2.1 \pm 0.1 \mathrm{~cm})$ were observed in plants cultured in a medium supplemented with 7 $\mathrm{mg} \mathrm{L}^{-1}$ of $\mathrm{AgNO}_{3}$ and $2 \mathrm{mg} \mathrm{L}^{-1} \mathrm{BAP}$; however, increasing the concentration of $\mathrm{AgNO}_{3}$ decreased the shoot regeneration and shoot length. The effect of different concentrations of the polyamine putrescine on shoot regeneration of $P$. tinctorium

Table 2. Effect of different concentrations of putrescine on shoot regeneration from stem internode explant cultures of Polygonum tinctorium after 5 weeks of culture on shoot regeneration medium (Murashige \& Skoog medium with 2 mg L-1 6-benzylaminopurine BAP)

\begin{tabular}{lcc}
\hline $\begin{array}{l}\mathrm{AgNO}_{3} \\
\left(\mathrm{mg} \mathrm{L}^{-1}\right)\end{array}$ & $\begin{array}{c}\text { No. of } \\
\text { shoots/explant }\end{array}$ & $\begin{array}{c}\text { Shoot } \\
\text { length }\end{array}$ \\
\hline 0 & $4.8 \pm 0.8$ & $1.8 \pm 0.1$ \\
10 & $5.5 \pm 0.6$ & $1.8 \pm 0.1$ \\
30 & $6.0 \pm 0.7$ & $2.1 \pm 0.1$ \\
50 & $7.4 \pm 0.8$ & $2.2 \pm 0.1$ \\
100 & $5.6 \pm 0.5$ & $1.9 \pm 0.1$ \\
200 & $4.6 \pm 0.8$ & $1.7 \pm 0.1$ \\
\hline
\end{tabular}

* Values represent the mean \pm standard deviation of 50 shoots 
was evaluated in the explants grown for 4 weeks. Significant increase in shoot regeneration and shoot length was observed in explants cultured in media supplemented with $50 \mathrm{mg} \mathrm{L}^{-1}$ putrescine and $2 \mathrm{mg} \mathrm{L}^{-1}$ BAP. Further increase in concentration of the polyamine decreased the shoot regeneration and shoot length. The highest shoot number (7.4 $\pm 0.8)$ and shoot length $(2.2 \pm 0.1)$ were observed at $50 \mathrm{mg} \mathrm{L}^{-1}$ putrescine with $2 \mathrm{mg} \mathrm{L}^{-1}$ BAP.

Plant tissue culture is an important tool for regeneration and micropropagation of various plants because of its requirement. For enhancement of the plant regeneration system, we investigated the effect of various concentrations of an ethylene inhibitor $\left(\mathrm{AgNO}_{3}\right)$ and a polyamine (putrescine) on the efficiency of shoot organogenesis in $P$. tinctorium. Previously established protocol for shoot organogenesis and plant regeneration from internode explants of $P$. tinctorium $^{19}$. Results suggested that the addition of $\mathrm{AgNO}_{3}$ and putrescine to the culture medium enhanced shoot regeneration of $P$. tinctorium (Tables 1 and 2).

Several studies reported that ethylene induces shoot regeneration and elongation in some plants $^{27}$. However, micropropagation of many plants is affected by the excessive production of ethylene and accumulation of ethylene reduces the regeneration frequency ${ }^{21}$. Therefore, ethylene inhibitors improve the regeneration and shoot length ${ }^{28}$. Herein, we added an anti-ethylene agent to the regeneration medium. Higher number of shoots and greater shoot length was achieved in Aloe arborescens Mill., using ethylene inhibitors ${ }^{29}$, and addition of $\mathrm{AgNO}_{3}$ improved the micropropagation and regeneration frequency in $\mathrm{XXX}^{30}$ and enhanced shoot number and shoot length in Sinningia speciosa ${ }^{22}$. To establish a regeneration method for $P$. tinctorium, we used different concentrations of the ethylene inhibitor. Previous studies revealed that treatment with 15 $\mathrm{mg} \mathrm{L}^{-1}$ of $\mathrm{AgNO}_{3}$ increased the number of shoots and shoot length in Musa acuminata $\mathrm{L}^{31}$, whereas treatment with $10 \mathrm{mg} \mathrm{L}^{-1}$ of $\mathrm{AgNO}_{3}$ increased the number of shoots in Aloe arborescens. In the present work, $7 \mathrm{mg} \mathrm{L}^{-1} \mathrm{AgNO}_{3}$ increased significantly the number of shoots and shoot length.

We also studied the effect of polyamine on the regeneration of P. tinctorium. Polyamines regulate growth and secondary metabolism in plants $^{32}$. Thus, they improve shoot regeneration in Cucumis sativus L. and Withania somnifera (L.) Dunal $^{33,34}$, enhance somatic embryogenesis via suspension cultures in spine gourd (Momordica dioica Roxb. ex. Willd. ${ }^{35}$, and enhance somatic embryogenesis and plant regeneration in upland cotton (Gossypium hirsutum L.) ${ }^{36}$. In the present work, we reported that $50 \mathrm{mg} \mathrm{L}^{-1}$ putrescine increased the number of shoots and shoot length in P. tinctorium. Herein, we used a highly efficient system of internode explants and anti-ethylene agent $\mathrm{AgNO}_{3}$ and polyamine putrescine for the invitro micropropagation of $P$. tinctorium. To our knowledge, this is the first study in which $\mathrm{AgNO}_{3}$ and polyamines were used for the regeneration of indigo plants.

\section{CONCLUSIONS}

Plant micropropagation protocols are the most important methods in tissue culture techniques used for induction of genetic transformation and plant growth improvement. Today, shoot organogenesis is the most widely used for in vitro plant regeneration in transformation systems. The protocol used in this study, which was employed successfully for regeneration of a large number of plants, was effective in the regeneration of $P$. tinctorium. The ethylene inhibitor $\mathrm{AgNO}_{3}$ and polyamine putrescine promoted the frequency of shoot organogenesis and shoot elongation in this species. Our findings might form the basis for the genetic improvement of $P$. tinctorium.

\section{REFERENCES}

1. Cooksey, C.J. Indigo: an annotated bibliography. Biotechnic and Histochemistry, 2007; 82: 105125.

2. Pawlak, K., Puchalska, M., Miszczak, A., Ros1oniec, E., Jarosz, M. Blue natural organic dye stuffs from textile dyeing to mural painting. Separation and characterization of coloring matters present in elderberry, logwood and indigo. J. Mass Spectrom., 2006; 41: 613-622.

3. Iwaki, K., Kurimoto, M. Cancer preventive effects of the indigo plant, Polygonum tinctorium. Recent Res. Dev. Cancer., 2002; 4: 429-437.

4. Mizuno, T. Nippon Yakusou Zensyo. Sin Nippon Houki, Japan, 1995. 5.

5. Miyata, S.K., Kimoto, T., Micallef, M.J., Hino, 
K., Taniguchi, M., Ushio, S., Iwaki, K., Ikeda, M., Kurimoto, M. Prevention of azoxymethaneinduced intestinal tumorsby a crude ethyl acetate-extract and tryptanthrin extracted from Polygonum tinctorium Lour, Anticancer Res., 2001; 21: 3295-3300.

6. Micallef, M.J., Iwaki, K., Ishihara, T., Ushio, S., Aga, M., Kunikata, T., Koya-Miyata, S., Kimoto, T., Ikeda, M., Hino, K., Kurimoto, M. The natural plant product tryptanthrinameliorates dextran sodium sulfateinduced colitis in mice, Int. Immunophar-macol., 2002; 2: 565-578.

7. Honda, G., Tabata, M., Isolation of antifungal principle tryptathrin, from Strobilanthes cusia O. Kuntze. Planta Med., 1979; 36: 85-86.

8. Koya-Miyata, S., Kimoto, T., Micallef, M.J., Hino, K., Taniguchi, M., Ushio, S., Iwaki, K., Ikeda, M., Kurimoto, M. Prevention of azoxymethane-induced intestinal tumors by a crude ethyl acetateextract and tryptanthrin extracted from Polygonum tinctorium Lour. Anticancer Res., 2001; 21: 3295-3300.

9. Kataoka, M., Hirata, K., Kunikata, T., Ushio, S., Iwaki, K., Ohashi, K., Ikeda, M., Kurimoto, M. Antibacterial action of tryptanthrin and kaempferol, isolated from the indigo plant (Polygonum tinctorium Lour.), against Helicobacter pylori-infected Mongolian gerbils. J. Gastroenterol. 2001; 36: 5-9.

10. Miyake, M., Arai, N., Ushio, S., Iwaki, K., Ikeda, M., Kurimoto, M. Promoting effect of kaempferol on the differentiation and mineralization of murine pre-osteoblastic cell line MC3T3-E1. Biosci. Biotechnol. Biochem., 2003; 67: 1199-1205.

11. Hunger, K. Industrial dyes. In: Chemistry, Properties, Applications. Wiley-VCH, Weinheim., 2007.

12. Meijer, L. (Ed.). Indirubin, the Red Shade of indigo. Life in Progress. 2006.

13. Stasiak, N., Kukula-Koch, W., G³owniak, K., Modern industrial and pharmacological applications of indigo dye and its derivatives-a review. Acta Pol. Pharm., 2014; 71: 215-221.

14. Kimoto, T., Hino, K., Koya-Miyata, S., Yamamoto, Y., Takeuchi, M., Nishizaki, Y.J., Micallef, M., Ushio, S., Iwaki, K., Ikeda, M., Kurimoto, M. Cell differentiation and apoptosis of monocytic and promyelocytic leukemia cells (U-937 and HL-60) by tryptanthrin, an active ingredient of Polygonum tinctorium Lour. Pathology International 2001; 51:315-325.

15. Honda, G., Tosirisuk, V., Tabata, M. Isolation of an antidermatophytic, tryptanthrin, from indigo plants, Polygonum tinctorium and Isatis tinctoria. Planta Med., 1980; 38:275-276.

16. Chandra, S., Bandopadhyay, R., Kumar, V., Chandra, R. Acclimatization of tissue cultured plantlets: from laboratory to land. Biotechnol Lett., 2010; 32:1199-1205.

17. Debnath, M., Malik, C.P., Bisen, P.S Micropropagation: a tool for the production of high quality plant-based medicines. Curr Pharm Biotechnol 2006; 7:33-49

18. Thorpe, T.A. History of plant tissue culture. Mol. Biotechnol. 2007; 37(2):169-180.

19. Thwe, A.A., Kim, Y.B., Kim, S.U., Park, S.U. In Vitro Shoot Regeneration from Stem Internodes of Polygonum tinctorium. Life Scie., 2012; 9(4)

20. Seong, E.S., Song, K.J., Jegal, S., Yu, C.Y., Chung, I.M. Silver nitrate and amino ethoxyvinylglycine affect Agrobacterium-mediated apple transformation. Plant Growth Regul., 2005; 45: 75-82.

21. Kumar, P.P., Lakshmanan, P., Thorpe, T.A. Regulation of morphogenesis in plant tissue culture by ethylene. In Vitro Cell Deve Biol Plant., 1998; 34(2), 94-103.

22. Chae, S.C., Kim, H.H., Park, S.U. Ethylene inhibitors enhance shoot organogenesis of Gloxinia (Sinningia speciosa). Scientific World J.. 2012.

23. Kumar, V., Parvatam, G., Ravishankar, G.A. AgNO3: a potential regulator of ethylene activity and plant growth modulator. Electron. J. Biotechnol., 2009; 12: 8-9.

24. Wang, G.L., Xu, Y.N. Hypocotyl-based Agrobacterium-mediated transformation of soybean (Glycine max) and application for RNA interference. Plant Cell Rep., 2008; 27: 11771184.

25. Gamma, T., Thomas, B., Muleo, R. Ethylene inhibitor silver nitrate enhance the regeneration and genetic transformation of Prunu savium (L) cv stella. Plant cell Tiss. Org. Cult., 2014; 120:7988.

26. Murashige, T., Skoog, F. A revised medium for rapid growth and bio assays with tobacco tissue cultures. Physiol Plant 1962; 15:473-497.

27. Trujillo-Moya, C., Gisbert, C. The influence of ethylene andethylene modulators on shoot organogenesis in tomato. Plant cell Tiss. Org. Cult., 2012; 111:41-48.

28. Pius, J., George, L., Eapen, S., Rao, P.S. Enhanced plant regeneration in pearl millet (Pennisetum americanum) byethylene inhibitors and cefotaxime. Plant cell Tiss. Org. Cult., 1993; 32: 91-96,

29. Suh, S.Y., Baskar, T.B., Kim, H.H., Al-Dhabi, N.A., Park, S.U., Ethylene inhibitors promote shoot organogenesis of Aloe arborescens Miller. 
South Indian Journal of Biological Sciences., 2015; 1(1): 43-46.

30. Kevers, C., le Gal, N., Monteiro, M., Dommes, J., Gaspar, T., le Gal, N. Somatic embryogenesis of Panax ginseng in liquidcultures: a role for polyamines and their metabolic pathways.Plant Growth Regul., 2000; 31: 209-214.

31. Tamimi. S.M. Effects of ethylene inhibitors, silver nitrate (AgNO3), cobalt chloride ( $\mathrm{CoCl} 2)$ and aminooxyacetic acid (AOA), on in vitro shoot induction and rooting of banana (Musa acuminata L.). Afr J Biotechnol, 2015; 14(32): 2510-2516

32. Bais, H.P., Ravishankar, G.A. Role of polyamines in the ontogeny of plants and their biotechnological applications. Plant cell Tiss. Org. Cult., 2002; 69: 1-34.

33. Vasudevan, A., Selvaraj, N., Ganapathi, A., Kasthurirengan, S., RameshAnbazhagan, V., Manickavasagam, M., Choi, C. Leucine andspermidine enhance shoot differentiation in cucumber (Cucumissativus L.). In Vitro Cell Dev Biol Plant., 2008; 44(4): 300-306.

34. Sivanandhan, G., Mariashibu, T.S., Arun, M., Rajesh, M., Kasthurirengan, S., Selvaraj, N., Ganapathi, A. The effect of polyamines onthe efficiency of multiplication and rooting of Withania somnifera(L.) Dunal and content of some with anolides in obtainedplants. Acta Physiol Plant., 2011; 33:2279-2288.

35. Thiruvengadam, M., Rekha, K.T., Jayabalan, N., Praveen, N., Kim, E.H., Chung, I.M. Effect of exogenous polyamines enhances somatic embryogenesis via suspension cultures of spine gourd (Momordica dioica Roxb. ex. Willd.). Astralian Journal of Crop Science., 2013; 7(3):446-453.

36. Sakhanokho, H.F., Akins, P.O., May, O.L., Chee, P.W. Putrescine enhances somatic embryogenesis and plant regeneration in upland cotton. Plant Cell Tiss Organ Cult., 2005; 81:91-95. 